\title{
Onapristone Extended Release: Safety Evaluation from Phase I-II Studies with an Emphasis on Hepatotoxicity
}

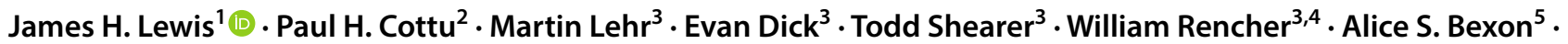 \\ Mario Campone $^{6} \cdot$ Andrea Varga $^{7} \cdot$ Antoine Italiano $^{8}$
}

Published online: 27 June 2020

(c) The Author(s) 2020

\begin{abstract}
Introduction Antiprogestins have demonstrated promising activity against breast and gynecological cancers, but liver-related safety concerns limited the advancement of this therapeutic class. Onapristone is a full progesterone receptor antagonist originally developed as an oral contraceptive and later evaluated in phase II studies for metastatic breast cancer. Because of liver enzyme elevations identified during clinical studies, further development was halted. Evaluation of antiprogestin pharmacology and pharmacokinetic data suggested that liver enzyme elevations might be related to off-target or metabolic effects associated with clinical drug exposure.

Objective We explored whether the use of a pharmaceutic strategy targeting efficacious systemic dose concentrations, but with diminished peak serum concentrations and/or total drug exposure would mitigate hepatotoxicity. Twice-daily dosing of an extended-release formulation of onapristone was developed and clinically evaluated in light of renewed interest in antiprogestin therapy for treating progesterone receptor-positive breast and gynecologic cancers. The hepatotoxic potential of extended-release onapristone was assessed from two phase I-II studies involving patients with breast, ovarian, endometrial, and prostate cancer. Results Among the 88 patients in two phase I-II studies in progesterone receptor-positive malignancies treated with extended-release onapristone, elevated alanine aminotransferase/aspartate aminotransferase levels were found in $20 \%$ of patients with liver metastases compared with $6.3 \%$ without metastases. Of five patients with grade 3 or higher alanine aminotransferase elevations with or without bilirubin elevations (four with breast cancer and one with endometrial cancer), four were assessed as unrelated to extended-release onapristone by the safety data review committee. Furthermore, while the fifth patient's liver enzyme elevations were considered possibly drug related by the study investigator, they were adjudicated as unlikely to be related ( $<25 \%$ likelihood) by a subsequent independent hepatologist.

Conclusions These results suggest that the extended-release formulation by reducing drug exposure may be associated with a reduced risk of hepatotoxicity, and supports the continued clinical evaluation of extended-release onapristone for treating progesterone receptor-positive cancers.
\end{abstract}

\section{Introduction}

Antiprogestins were first developed in the 1980s as oral contraceptives to block the maturation of the endometrium and subsequent ovulation [1]. Development expanded into oncology after it was learned that tamoxifen, an antiestrogen, stimulated progesterone synthesis in patients with breast

James H. Lewis and Paul H. Cottu contributed equally to the article

James H. Lewis

lewisjh@gunet.georgetown.edu

Extended author information available on the last page of the article cancer [2]. Five antiprogestins (mifepristone, ulipristal, telapristone, lonaprisan, and onapristone) were clinically evaluated in gynecological and breast cancers [3-9]. In breast cancer, clinical trials with mifepristone, lonapristone, and onapristone demonstrated partial responses, with onapristone showing the most robust clinical benefit [3-7, 9]. In two phase I-II studies, onapristone exhibited a $56 \%$ overall response rate and a $67 \%$ clinical benefit rate in patients with locally advanced, hormone therapy-naïve metastatic breast cancer [4], and a $10 \%$ overall response rate and a $49 \%$ clinical benefit rate [6] in metastatic tamoxifen-resistant patients. The Robertson et al. and Jonat et al. studies indicated that onapristone could have a clinically meaningful impact on endocrine treatment of breast cancer. However, liver test 


\section{Key Points}

Onapristone is a full progesterone receptor antagonist that was originally developed as an oral contraceptive and shown to have efficacy in breast cancer and other malignancies.

Liver enzyme elevations led to a halt in its original development program.

A review of antiprogestin pharmacology and pharmacokinetic data suggests that liver enzyme elevations observed in clinical trials with onapristone might be related to off-target effects associated with serum maximum plasma concentrations, which are mitigated by the extended-release formulation.

abnormalities were seen in one-third of patients with hormone therapy-naïve metastatic breast cancer and, according to Robertson et al., "One or more LFT [liver function test] was elevated in the first 6 weeks of treatment and usually declined thereafter at a steady rate" [4]. Schering stopped development of onapristone, as well as recruitment into Robertson et al.'s study after the 19th patient in 1995, even though "Two-thirds of patients obtained a clinically relevant tumour remission ..." [4].

Antiestrogens are extensively used in oncology to inhibit estrogen receptor (ER) signaling. However, there are efficacy limits with these drugs, and findings that progesterone receptor (PR) activity modulates estrogen signaling in PR-positive $(\mathrm{PR}+), \mathrm{ER}$-positive $(\mathrm{ER}+)$ breast cancers has led to renewed interest in antiprogestins as therapies for breast and gynecologic cancers [10-15]. Another factor driving renewed interest in antiprogestins has been biomarker advances enabling patients to be identified whose tumor genetics and PR target gene signatures make them most likely to benefit from antiprogestin therapy $[16,17]$. Since onapristone demonstrated, in breast cancer trials, the most promising clinical benefit among clinical-stage antiprogestins, it was selected for a reformulation program-with the hypothesis that altering onapristone pharmacokinetic (PK) properties might result in levels of efficacy seen in earlier cancer trials, but with a possibly reduced risk for hepatotoxicity.

While there are many mechanisms of drug-induced liver injury (DILI) [19, 20], as the human liver does not express appreciable levels of PR [21, 22], the etiology of onapristone-associated DILI may reflect drug metabolism toxicity or the modulation of other signaling pathways. To evaluate potential drug metabolism toxicity and support the re-introduction of onapristone into the clinic, ARNO Therapeutics (IND subsequently transferred to Context Therapeutics) synthesized onapristone under good manufacturing practice conditions and carried out a pre-IND toxicology program. ARNO further performed a non-clinical hepatic profile involving two in vitro and one in vivo liver-focused non-clinical safety studies: (a) Hepatopac ${ }^{\mathrm{TM}}$ models for murine and human primary hepatocytes; (b) a sandwich-cultured hepatocyte-based in vitro assay commonly used to identify compounds that might cause cholestasis; and (c) an evaluation of onapristone dosing in mice with humanized livers. These non-clinical, in vitro and in vivo, liver-focused toxicology studies found no significant hepatotoxicities and no lethalities associated with onapristone or its primary metabolite at dosing up to $50 \mu \mathrm{M}$, in vitro or up to $30 \mathrm{mg} / \mathrm{kg}$ in study animals dosed for 32 days (Context Therapeutics, data on file). Results of the pre-IND toxicology and non-clinical hepatic profile did not suggest a hepatic safety signal. However, as non-clinical studies cannot exclude hepatotoxicity in the clinic, careful liver test monitoring practices for ONA-ER were followed in the NCT02052128 and NCT02049190 studies and continue to be used in the NCT03909152 study.

The concept behind reformulating onapristone was to attempt to achieve the efficacy seen in the previous phase II studies of breast cancer [4, 6] while reducing the risk of DILI. Off-target effects on hepatic glucocorticoid receptors (GRs) are a plausible cause for hepatotoxicity seen in clinical trials. Several lines of evidence support this hypothesis, including: onapristone cross-reactivity with GR in liver cytosol [23]; onapristone cross-reactivity with GR and other steroid receptors closely related to PR in non-hepatic tissues [24-27]; and the recent demonstration that a closely related antiprogestin, ulipristal, specifically inhibits GR signaling in human liver cells [28]. As onapristone binds to GRs less efficiently than to PRs [24, 26, 27, 29], one strategic goal for reducing off-target effects was to reduce maximum concentration $\left(C_{\max }\right)$. Even if a mechanism apart from GR cross-reactivity underlies or contributes to onapristone-associated hepatotoxicity, reducing $C_{\max }$ can potentially reduce hepatotoxicity.

Another goal of onapristone reformulation is to achieve therapeutic efficacy levels seen in prior breast cancer studies $[4,6]$. In this regard, two factors affect a reformulation strategy. First, PRs require sustained suppression because PR transcriptional complexes undergo rapid turnover [30, 31]. Second, the promising clinical benefits reported in earlier breast cancer studies suggest that onapristone $100 \mathrm{mg}$ once daily (QD) achieves a minimum plasma concentration 
$\left(C_{\text {min }}\right)$ sufficient to achieve sustained PR suppression in at least some patients $[4,6]$. It is therefore desirable to achieve a $C_{\min }$ approximating the steady-state $C_{\min }$ with oral dosing at $100 \mathrm{mg}$ QD. Various formulation strategies were evaluated, and a 50-mg, BID (twice-daily), extended-release tablet (onapristone extended release; ONA-ER) was selected to be the dosage form for the clinical evaluation of onapristone in $\mathrm{PR}+$ cancers.

To date, ONA-ER has advanced into two, completed phase 1-2 studies in female subjects with PR+ endometrial breast or ovarian cancer (NCT02052128, Cottu et al., 2018) [8] and in male subjects with $\mathrm{PR}+$, castrate-resistant prostate cancer (NCT02049190; Jayaram et al., 2017) [18], while a further phase II basket study has recently been initiated in women with $\mathrm{PR}+$ recurrent gynecologic cancer (NCT03909152). In view of hepatotoxicity concerns from earlier clinical studies with onapristone and to better understand whether ONA-ER offers a suitable safety profile for continued evaluation in breast and gynecological cancers, we undertook a review of ONA-ER safety based on pooled data from a total of 88 subjects from NCT02052128 [8] and NCT02049190. [18].

\section{Methods}

To assess the hepatotoxic potential for ONA-ER in humans, this study evaluated two clinical studies in which ONA-ER was dosed between 10 and $50 \mathrm{mg}$ BID for up to 60 weeks (NCT02052128, published as Cottu et al., 2018; NCT02049190; clinical study records) [8]. Pharmacokinetic parameters were compared between onapristone $100 \mathrm{mg}$ QD (dosed as four times onapristone 25-mg capsules) and ONA-ER $50 \mathrm{mg}$ BID within a dose-escalation component of a phase I-II clinical study in female subjects with endometrial carcinoma, breast cancer, or ovarian cancer [8]. Blood samples were collected at $0,1,2,3,4,6,8$, and $12 \mathrm{~h}$ (before next ONA-ER BID dose), and at $24 \mathrm{~h}$ (before next 100-mg dose in capsules) post-drug dosing, as well as at hour 0 on days 8, 29, and 57 (just before drug intake). No dose-limiting toxicity was observed with repeated liver biochemical tests in the phase I component of NCT02052128, which defined a recommended phase II dose level of ONA-ER of $50 \mathrm{mg}$ BID.

The PK dataset from this clinical study enabled a direct comparison between $C_{\max }$ and steady-state trough concentrations $\left(C_{\text {min-ss }}\right)$ onapristone $100 \mathrm{mg}$ QD (capsular form) and ONA-ER $50 \mathrm{mg}$ BID. Figure 1 presents this comparison of the PK results. Figure 1 shows that dosing with ONA-ER $50 \mathrm{mg}$ BID resulted in the day 1 median $C_{\max }$ more than two times lower than the day 1 median $C_{\max }$ for onapristone $100 \mathrm{mg}$ QD, while at steady state (days 8, 29, 57), the median $C_{\text {min-ss }}$ for both formulations were similar:
$1504 \mathrm{ng} / \mathrm{mL}$ vs $1835 \mathrm{ng} / \mathrm{mL}$ for onapristone $100 \mathrm{mg}$ QD vs ONA-ER $50 \mathrm{mg}$ BID, respectively. The reduced day 1 $C_{\text {max }}$ observed for ONA-ER $50 \mathrm{mg}$ BID was associated with a delayed median time to $C_{\max }$ of $2.5 \mathrm{~h}$ vs $1 \mathrm{~h}$ for onapristone $100 \mathrm{mg}$ QD, indicating a reduced absorption rate for the ER formulation. The $C_{\max }$ and $C_{\min , \mathrm{ss}}$ for plasma concentrations for onapristone $100 \mathrm{mg}$ also exhibited greater variability compared with ONA-ER. While steady-state $C_{\max }$ concentrations were not available for a direct comparison, given the $C_{\min , \mathrm{ss}}$ concentrations were similar it can be reasonably assumed that steady-state $C_{\max }$ concentrations for onapristone $100 \mathrm{mg}$ will greatly exceed the concentrations observed following administration of ONA-ER $50 \mathrm{mg}$ BID. With respect to the $C_{\max }$ and $C_{\min , \mathrm{ss}}$, the findings shown in Fig. 1 support the reformulation thesis.

\subsection{Clinical Safety Review}

The databases of clinical trials AR18-CT-101 (NCT02052128, published as Cottu et al. 2018) and AR18CT-102 (NCT02049190; clinical study records) were reviewed and all subjects with either a hepatobiliary system

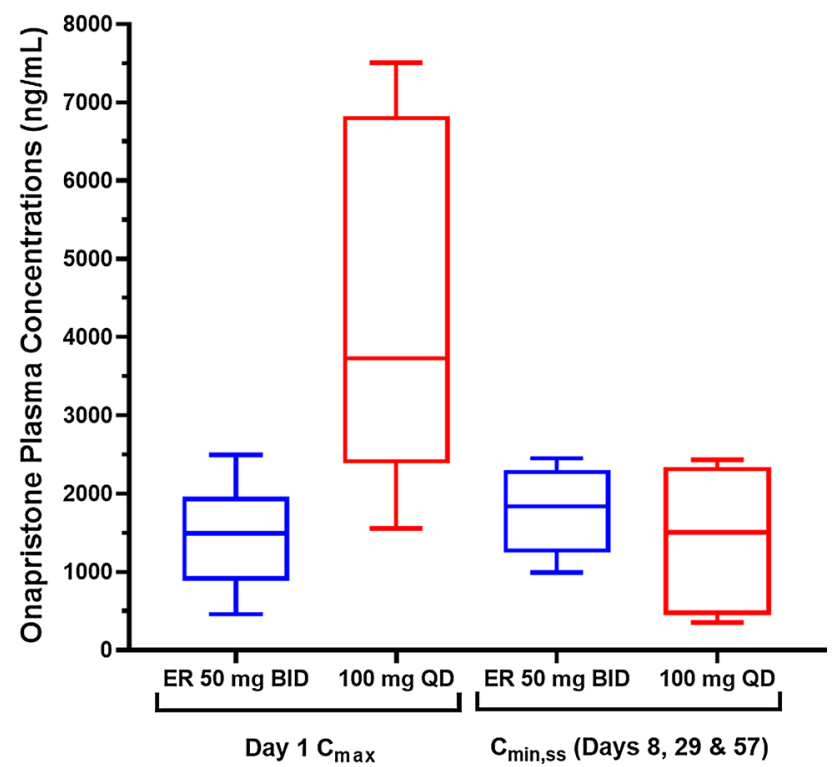

Fig. 1 Onapristone (simple oral tablet) vs onapristone extendedrelease (ER) pharmacokinetics on dosing day 1 and at steady state. Onapristone $100 \mathrm{mg}$ once daily (QD) [capsule form] and onapristoneER $50 \mathrm{mg}$ twice daily (BID); day 1 maximum concentration $\left(C_{\max }\right)$ and steady-state trough concentrations $\left(C_{\min , s s}\right)$. Day $1 C_{\max }$ for onapristone-ER $50 \mathrm{mg}$ BID and onapristone $100 \mathrm{mg}$ QD and $C_{\min }$,ss measured on days 8,29 , and 57 . The midline on the bars represents the median, while the whiskers represent the individual $C_{\min }$ and $C_{\max }$ observed within each group. The box below the median represents the second quartile $(\mathrm{Q} 2)$, while the box above the median represents the third quartile $(\mathrm{Q} 3)$ 
organ class adverse event (AE) or elevation of any liverrelated laboratory tests including alanine aminotransferase (ALT), aspartate aminotransferase (AST), bilirubin, gammaglutamyl transpeptidase (GGT), alkaline phosphatase (ALP), or lactic dehydrogenase were selected for additional evaluation [8].

The cumulative exposure to ONA-ER for all subjects included in the AR18-CT-101 and AR18-CT-102 studies was estimated from the clinical databases. For crossover and dose escalation studies, the number of subjects who received a given treatment in any included study period was counted. The safety cohort, if available, and assigned treatment cohorts were used to determine exposure in ongoing studies; if the safety population was not available, all subjects were included.

A review of pooled safety data of AR18-CT-101 and AR18-CT-102 studies was also conducted to evaluate potential correlations between: the presentation of liver metastases and liver enzyme abnormalities; the presentation of bone metastases and liver enzyme abnormalities; and the use of ONA-ER alone or in combination with abiraterone (abiraterone acetate plus prednisone). The Common Terminology Criteria for Adverse Events (version 5.0) was used to grade the aminotransferase elevations that occurred during the studies (Table 1).

\section{Results}

\subsection{Evaluation of Liver Test Abnormalities Observed in Phase I and Phase I-II Studies}

A total of 88 subjects have been dosed with ONA-ER in two oncology studies: (a) in AR18-CT-101 (phase I-II; NCT02052128) and (b) AR18-CT-102 (phase I-II; NCT02049190) (Table 2) [8, 18]. Drug-induced liver injury remains a diagnosis of exclusion after evaluating for various toxic, infectious, metabolic, and autoimmune causes of liver injury [32]. The lack of a definitive laboratory or radiologic test and the presence of non-specific histopathological findings can make DILI a challenging diagnosis [33]. For this reason, and to monitor safety and tolerability, a safety data review committee (DRC) was established, involving five independent members (two oncologists, one pharmacovigilance specialist [chair], one statistician, one clinical pharmacologist), as well as the lead principal investigator. Adverse events (AEs), including abnormal laboratory test results, were collected until 30 days after the last onapristone dose. Liver biochemical tests were monitored weekly for the first 8 weeks, then every 2 weeks. The study protocols and investigator brochure clearly stated that onapristone had been associated with liver test abnormalities and provided
Table 1 Common Terminology Criteria for Adverse Events version 5.0 grading system
Table 2 Clinical trials in which subjects received onapristone extended release (ONA-ER)

\begin{tabular}{lllll}
\hline & Grade 1 & Grade 2 & Grade 3 & Grade 4 \\
\hline Bilirubin & $0-1.5 \times \mathrm{ULN}$ & $1.5-3.0 \times \mathrm{ULN}$ & $3.0-10 \times \mathrm{ULN}$ & $>10 \times \mathrm{ULN}$ \\
AST/ALT & $0-3.0 \times \mathrm{ULN}$ & $3.0-5.0 \times \mathrm{ULN}$ & $5.0-20 \times \mathrm{ULN}$ & $>20 \times \mathrm{ULN}$ \\
\hline
\end{tabular}

$A L T$ alanine aminotransferase, $A S T$ aspartate aminotransferase, $U L N$ upper limit of normal

\begin{tabular}{|c|c|c|}
\hline Study & Study title & Dosage and dosage subjects $(n)$ \\
\hline $\begin{array}{l}\text { NCT02052128 (AR18-CT- } \\
101)^{\mathrm{a}}\end{array}$ & $\begin{array}{l}\text { Phase 1-2 Study of Onapristone in Patients } \\
\text { with Progesterone Receptor Expressing } \\
\text { Cancers }\end{array}$ & $\begin{array}{l}\text { Phase I } \\
\text { (a) ONA-ER BID: 10, 20, 30, } \\
40,50 \mathrm{mg}(n=46) \\
\text { (b) ONA } 100 \mathrm{mg} \text { QD }(n=6) \\
\text { Phase II } \\
\text { (a) ONA-ER BID } 50 \mathrm{mg} \\
\quad(n=6)\end{array}$ \\
\hline $\begin{array}{l}\text { NCT02049190 (AR18-CT- } \\
\text { 102) }\end{array}$ & $\begin{array}{l}\text { Phase 1-2 Study of Onapristone in Patients } \\
\text { with Advanced Castration-resistant Pros- } \\
\text { tate Cancer }\end{array}$ & $\begin{array}{l}\text { (a) ONA-ER BID: } 10,20,30 \text {, } \\
40,50 \mathrm{mg}(n=21) \\
\text { (b) ONA-ER } 30 \mathrm{mg} \text { BID + abi- } \\
\text { raterone } 1000 \mathrm{mg}(n=5)^{\mathrm{c}} \\
\text { (c) ONA-ER } 50 \mathrm{mg} \text { BID + abi- } \\
\text { raterone } 1000 \mathrm{mg}(n=10)^{\mathrm{c}}\end{array}$ \\
\hline
\end{tabular}

$B I D$ twice daily, $Q D$ once daily

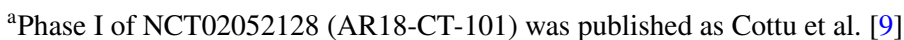

${ }^{\mathrm{b}}$ All subjects had histologically confirmed adenocarcinoma of the prostate that had progressed on abiraterone or enzalutamide. NCT02049190 was published as Jayaram et al. [18]

${ }^{\mathrm{c}}$ Abiraterone acetate $1000 \mathrm{mg}$ QD was dosed with prednisone $5 \mathrm{mg}$ BID 
extensive dose-limiting toxicity rules, DRC decision-making instructions, and dose interruption and reduction guidelines in the case of significant liver test elevations.

\subsection{Demographics and Other Characteristics of the Pooled Study Population}

A total of 88 subjects were included in the ONA-ER formulation pooled safety analysis. Subject demographics are given in Table 3.

\subsection{Adverse Events in the Pooled Study Population}

\subsubsection{Overall Onapristone Extended Release (ONA-ER)-Related Treatment-Associated Adverse Events}

Fifty-four subjects (61.4\%) of the total ONA-ER safety set $(n=88)$ experienced any drug-related AE. Adverse events were generally consistent across all defined groups. Higher incidences of AEs were observed in subjects who received abiraterone $(66.7 \%)$, and those with liver metastases from breast cancer $(76.2 \%)$.

All liver-related treatment-emergent AEs are summarized in Table 4. Among subjects with known liver metastases, $20 \%$ had raised ALT and AST, compared with $6.3 \%$ of subjects without liver metastases, as shown in Table 4.

Increased total serum bilirubin levels were seen in three subjects, two of whom had liver metastases, and in a third subject who had Gilbert syndrome. Increased blood ALP was observed in $20 \%$ of subjects with known liver
Table 3 Subject demographics of the onapristone extended release (ONA-ER) pooled safety analysis $(n=88)$

\begin{tabular}{ll}
\hline Demographic & $n(\%)$ \\
\hline Female & $52(59.1)$ \\
Male & $36(40.9)$ \\
Age, median (range) & $68.0(36-89)$ \\
$>65$ years & $61(69.3)$ \\
Ethnicity & \\
African ancestry & $0(0)$ \\
Asian & $0(0)$ \\
Caucasian & $87(98.9)$ \\
Unknown & $1(0.9)$ \\
Tumor type & \\
Endometrial/uterine & $19(21.5)$ \\
Ovarian & $12(13.6)$ \\
Breast & $21(23.9)$ \\
Prostate & $36(41.0)$ \\
Metastases & \\
Liver & $25(28.4)$ \\
Bone & $42(47.7)$ \\
Treatment & \\
ONA-ER & $73(83.0)$ \\
ONA-ER+ abiraterone & $15(17.0)$ \\
\hline
\end{tabular}

metastases, compared with $1.6 \%$ of subjects not known to have liver metastases. Alkaline phosphatase may also be a byproduct of bone metastases [34, 35]. Gamma-glutamyl transferase was increased relative to baseline in $32.0 \%$ of subjects with liver metastases and in $23.8 \%$ of subjects with

Table 4 Liver-related onapristone extended-release treatment-emergent adverse events (TEAEs) [all grades] in the safety dataset $(n=88)$

\begin{tabular}{|c|c|c|c|c|c|c|c|}
\hline TEAE & $\begin{array}{l}\text { Overall (AR18- } \\
\text { CT-101 + AR18- } \\
\text { CT-102) } \\
(N=88) \\
n(\%)\end{array}$ & $\begin{array}{l}\text { Without } \\
\text { abiraterone/ } \\
\text { prednisone } \\
(N=73) \\
n(\%)\end{array}$ & $\begin{array}{l}\text { With abira- } \\
\text { terone/pred- } \\
\text { nisone } \\
(N=15) \\
n(\%)\end{array}$ & $\begin{array}{l}\text { Without } \\
\text { liver metas- } \\
\text { tases } \\
(N=63) \\
n(\%)\end{array}$ & $\begin{array}{l}(N=25) \\
n(\%)\end{array}$ & $\begin{array}{l}\text { Without } \\
\text { bone metas- } \\
\text { tases } \\
(N=46) \\
n(\%)\end{array}$ & $\begin{array}{l}(N=42) \\
n(\%)\end{array}$ \\
\hline Hepatobiliary disorders & $1(1.1)$ & $1(1.4)$ & $0(0.0)$ & $1(1.6)$ & $0(0.0)$ & $0(0.0)$ & $1(2.4)$ \\
\hline Hepatocellular injury & $1(1.1)$ & $1(1.4)$ & $0(0.0)$ & $1(1.6)$ & $0(0.0)$ & $0(0.0)$ & $1(2.4)$ \\
\hline ALT increased & $9(10.2)$ & $8(11.0)$ & $1(6.7)$ & $4(6.3)$ & $5(20.0)$ & $3(6.5)$ & $6(14.3)$ \\
\hline AST increased & $11(12.5)$ & $11(15.1)$ & $0(0.0)$ & $6(9.5)$ & $5(20.0)$ & $3(6.5)$ & $8(19.0)$ \\
\hline Blood bilirubin increased & $3(3.4)$ & $3(4.1)$ & $0(0.0)$ & $1(1.6)$ & $2(8.0)$ & $1(2.2)$ & $2(4.8)$ \\
\hline Conjugated bilirubin increased & $2(2.3)$ & $1(1.4)$ & $1(6.7)$ & $2(3.2)$ & $0(0.0)$ & $2(4.3)$ & $0(0.0)$ \\
\hline Blood ALP increased & $6(6.8)$ & $5(6.8)$ & $1(6.7)$ & $1(1.6)$ & $5(20.0)$ & $1(2.2)$ & $5(11.9)$ \\
\hline GGT increased & $14(15.9)$ & $13(17.8)$ & $1(6.7)$ & $6(9.5)$ & $8(32.0)$ & $4(8.7)$ & $10(23.8)$ \\
\hline
\end{tabular}

Safety population $=$ all subjects who receive at least one dose of onapristone. $N=$ number of subjects in the safety population and subgroup $n=$ number of subjects with an event. Related adverse events = related to onapristone for AR18-CT-101 and AR18-CT-102 or abiraterone/prednisone for AR18-CT-102. Studies: AR18-CT-101 and AR18-CT-102

$A L P$ alkaline phosphatase, $A L T$ alanine aminotransferase, $A S T$ aspartate aminotransferase, $G G T$ gamma-glutamyl transpeptidase 
bone metastases, compared with approximately $9.0 \%$ of subjects without bone or liver metastases. It is hypothesized that GGT may be overexpressed in certain tumor cells, and may play a role in tumor progression [36, 37]. Gamma-glutamyl transferase and ALP were increased relative to baseline in five subjects (7.9\%) with liver and bone metastases and one subject (4.0\%) who had no liver or bone metastases. Concurrent GGT and ALP elevations were low grade and mainly associated with metastases.

\subsubsection{ONA-ER-Related Treatment-Emergent Adverse Events and Liver Metastases}

Subjects with known liver or bone metastases experienced the majority of grade 3 or 4 liver test abnormalities (Table 5). The clinical significance of GGT elevation in the setting of advanced cancer is not clear, although as noted above, there is a suggestion that certain tumor cells may overexpress GGT, and that GGT may play a role in tumor progression $[36,37]$. There were no subjects who had concurrent GGT and ALP grade 3 or higher treatment-emergent AEs. Importantly, no patient developed concurrent ALT more than three times the upper limit of normal and total bilirubin more than two times the upper limit of normal, with or without an elevation in alkaline phosphatase.

\subsection{Hepatic Safety Events in Clinical Trials of ONA-ER}

\subsubsection{Phase I-II Study in Female Subjects with Progesterone Receptor-Expressing Cancers (Study AR18-CT-101; NCT02052128; Cottu et al. 2018; Context Therapeutics, Study on File)}

AR18-CT-101 (NCT02052128) was a phase I-II study of female subjects ( $n=58, n=52$ received ONA-ER) with PR-expressing cancers [8]. Five subjects, four with breast cancer and one with endometrial cancer, developed significant elevations in liver tests and serum bilirubin suggesting cholestatic injury. All four subjects with breast cancer had grade 3 liver test elevations in conjunction with rapid disease progression (Table 6). Although site investigators reported each case as possibly related to onapristone, a subsequent DRC review judged them to be unrelated to onapristone and, therefore, not dose-limiting toxicities.

Two subjects (0003-0002 and 0014-0005) underwent a dose reduction or interruption because of elevated liver enzymes. For subject 0003-0002, review of the pharmacovigilance CIOMS I form for this subject revealed that the liver disease was obstructing the biliary duct and was treated with a biliary drain/stent 2 days after stopping ONA-ER. This explains the causation and the immediate resolution of liver enzyme events. For subject 0014-0005, at the day 29 visit, the subject complained of mild abdominal pain,

Table 5 Liver-related onapristone extended release (ONA-ER) grade 3-4 treatment-emergent adverse events (TEAEs) in the safety dataset $(n=88)$

\begin{tabular}{|c|c|c|c|c|c|c|c|}
\hline TEAE & $\begin{array}{l}\text { Overall (AR- } \\
18-\mathrm{CT} 101+\text { AR18- } \\
\text { CT102) } \\
(N=88) \\
n(\%)\end{array}$ & $\begin{array}{l}(N=73) \\
n(\%)\end{array}$ & $\begin{array}{l}(N=15) \\
n(\%)\end{array}$ & $\begin{array}{l}\text { Without } \\
\text { liver metas- } \\
\text { tases } \\
(N=63) \\
n(\%)\end{array}$ & $\begin{array}{l}(N=25) \\
n(\%)\end{array}$ & $\begin{array}{l}\text { Without } \\
\text { bone metas- } \\
\text { tases } \\
(N=46) \\
n(\%)\end{array}$ & $\begin{array}{l}(N=42) \\
n(\%)\end{array}$ \\
\hline ALT increased & $1(1.1)$ & $1(1.4)$ & $0(0.0)$ & $0(0.0)$ & $1(4.0)$ & $0(0.0)$ & $1(2.4)$ \\
\hline AST increased & $4(4.5)$ & $4(5.5)$ & $0(0.0)$ & $1(1.6)$ & $3(12.0)$ & $2(4.3)$ & $2(4.8)$ \\
\hline Blood ALP increased & $3(3.4)$ & $3(4.1)$ & $0(0.0)$ & $0(0.0)$ & $3(12.0)$ & $0(0.0)$ & $3(7.1)$ \\
\hline Blood bilirubin increased & $2(2.3)$ & $2(2.7)$ & $0(0.0)$ & $0(0.0)$ & $2(8.0)$ & $0(0.0)$ & $2(4.8)$ \\
\hline GGT increased & $9(10.2)$ & $8(11.0)$ & $1(6.7)$ & $3(4.8)$ & $6(24.0)$ & $4(8.7)$ & $5(11.9)$ \\
\hline $\begin{array}{c}\text { ALT }>3 \times \text { and biliru- } \\
\text { bin }>2 \times \text { ULN }\end{array}$ & $0(0.0)$ & $0(0.0)$ & $0(0.0)$ & $0(0.0)$ & $0(0.0)$ & $0(0.0)$ & $0(0.0)$ \\
\hline $\begin{array}{l}\text { ALT }>3 \times \text { and biliru- } \\
\text { bin }>2 \times \text { with ALP }>2 \times\end{array}$ & $0(0.0)$ & $0(0.0)$ & $0(0.0)$ & $0(0.0)$ & $0(0.0)$ & $0(0.0)$ & $0(0.0)$ \\
\hline
\end{tabular}

Safety population $=$ all subjects who received at least one dose of ONA-ER in clinical studies: AR18-CT-101 and AR18-CT-102. ONA-ER related adverse events $=$ (a) related to ONA-ER for AR18-CT-101 and AR18-CT-102 or (b) ONA-ER plus abiraterone/prednisone for AR18CT-102. $N=$ number of subjects in the safety population or the sub-group of the safety population (e.g., $N=73$ subjects who were not treated with abiraterone). $n$ number of subjects with an event

$A L P$ alkaline phosphatase, $A L T$ alanine aminotransferase, $A S T$ aspartate aminotransferase, $G G T$ gamma-glutamyl transpeptidase, $U L N$ upper limit of normal 
Table 6 IND hepatic safety reports in subjects with breast cancer (AR18-CT-101)

\begin{tabular}{|c|c|c|c|c|c|}
\hline Age, years & Event & $\begin{array}{l}\text { CTCAE } \\
\text { grade }\end{array}$ & DRC causality determination & Action taken & Outcome $^{\mathrm{b}}$ \\
\hline 63 & Bilirubin increase & 3 & $\begin{array}{l}\text { Unrelated; due to bile duct obstruction from liver metastases } \\
\text { requiring biliary stenting }\end{array}$ & Drug discontinued & Improved \\
\hline 57 & Bilirubin increased & 3 & Unrelated; due to progressive liver and bone metastases & $\mathrm{NA}^{\mathrm{a}}$ & Not resolved \\
\hline 60 & AST/ALT increased & 3 & $\begin{array}{l}\text { Unrelated; due to progression of disease with malignant ascites } \\
\text { and pleural effusion that later improved with start of gemcit- } \\
\text { abine and eribulin }\end{array}$ & $\mathrm{NA}^{\mathrm{a}}$ & Resolved \\
\hline 42 & AST increased & 3 & Unrelated; due to progressive liver metastases & $\mathrm{NA}^{\mathrm{a}}$ & Not resolved \\
\hline
\end{tabular}

$A L T$ alanine aminotransferase, $A S T$ aspartate aminotransferase, CTCAE Common Terminology Criteria for Adverse Events, version 4.03, DRC data review committee, $N A$ not applicable, TESAE treatment-emergent serious adverse event

${ }^{a}$ No action taken because ONA-ER was already discontinued for progressive disease

${ }^{\mathrm{b}}$ Outcome as per TESAE site report—does not necessarily represent final clinical study report

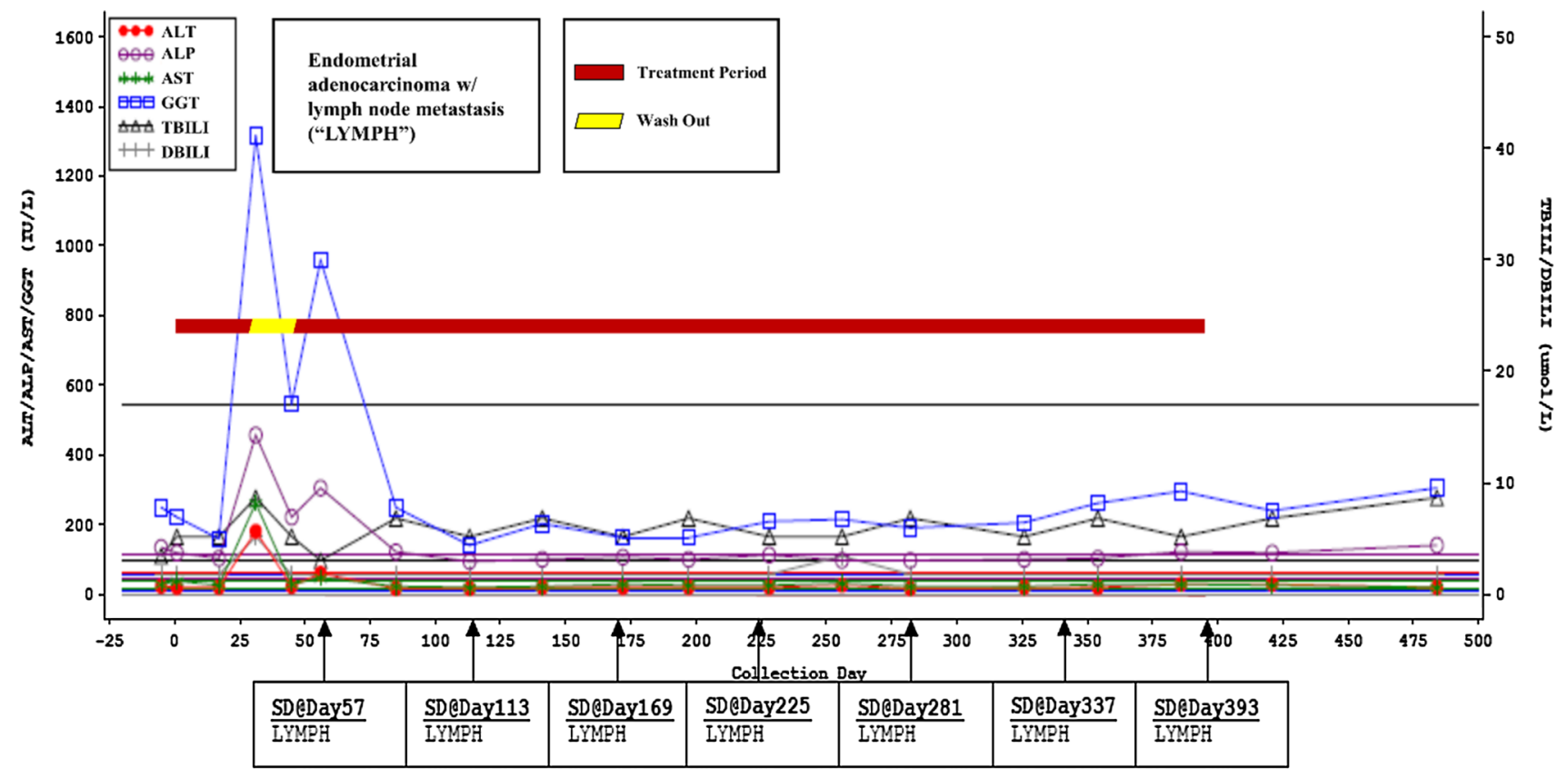

Fig. 2 Subject 0014-0005 graphical profile. Safety population=all subjects who received at least one dose of onapristone. Collection day is calculated relative to the date of randomization (day 1). Alanine transaminase (ALT), aspartate transaminase (AST), alkaline phosphatase (ALP), and gamma-glutamyl transpeptidase (GGT) are

and liver enzyme tests identified non-serious elevations of GGT and ALP. Both ONA-ER and the only concomitant medication, tranexamic acid, were stopped temporarily until the values regressed. Gamma-glutamyl transpeptidase and ALP levels returned to baseline by day 43; and then both ONA-ER, at a one-level dose reduction (37.5 mg BID), and tranexamic acid were restarted. All liver tests were within the normal range by day 85 despite continuation of treatment with ONA-ER and tranexamic acid. Figure 2 illustrates the plotted relative to the left axis (IU/L) and total bilirubin (TBILI) and direct bilirubin (DBILI) are plotted relative to the right axis ( $\mu \mathrm{mol} / \mathrm{L})$. For each parameter, reference lines for one times the upper limit of normal are provided

time course of liver tests for subject 0014-0005. Although the work-up for other causes was limited, an independent assessment of this case by a hepatologist (J.H.L.) concluded that this hepatic event was unlikely to be related to ONA-ER ( $<25 \%$ probability based on the US Drug-Induced Liver Injury Network scoring system) [38] largely due to the negative re-challenge response to ONA-ER that was continued without further incident. 


\subsubsection{Phase I-II Study in Male Subjects with Castrate-Resistant Prostate Cancer (Study AR18-CT-102; NCT02049190)}

The clinical study AR18-CT-102 (NCT02049190) was a phase I-II study in male subjects $(n=36)$ with castrationresistant prostate cancer, in which all subjects had histologically confirmed adenocarcinoma of the prostate that had progressed on abiraterone or enzalutamide [18]. Subjects were divided among seven treatment cohorts who were dosed with: ONA-ER BID: 10, 20, 30, 40, or $50 \mathrm{mg}$; ONA-ER $30 \mathrm{mg}$ BID plus abiraterone (abiraterone acetate $1000 \mathrm{mg}$ plus prednisone $5 \mathrm{mg}$ BID); or ONA-ER $50 \mathrm{mg}$ BID plus abiraterone. There were no serious AEs related to liver biochemistry tests, including 15 subjects who received abiraterone in combination with ONA-ER. This is a relevant observation because abiraterone has been reported to cause liver toxicity in its own right $[39,40]$. None of the subjects had significant liver metastases. There were no deaths related to ONA-ER or deaths due to liver-related AEs in this study.

\section{Discussion}

Onapristone is a unique full PR antagonist that prevents $\mathrm{PR}$ activation and consequent PR-induced transcription [41, 42]. The non-clinical efficacy of onapristone has been documented in multiple preclinical tumor models as a single agent, as well as in combination with anti-estrogens [43, 44]. The clinical efficacy of onapristone has been demonstrated in multiple clinical trials in subjects with breast, ovarian, or endometrial cancers $[4,6,8]$. Compared to subjects with breast cancer treated with other antiprogestins (mifepristone, lonapristone), onapristone showed the most robust clinical benefit $[3,5,7,9]$. These findings indicated that onapristone could have a clinically meaningful impact on endocrine treatment of breast cancer. However, concerns around DILI led to onapristone development being discontinued by the original sponsor [4].

A renewed interest in antiprogestin therapy for PR+ tumors stems from findings that PR activity governs estrogen signaling in $\mathrm{ER}+, \mathrm{PR}+$ breast cancers by regulating chromatin binding of ERalpha and modulating the bioavailability of RNA polymerase III-transcribed transfer RNA molecules needed for tumor growth [12-14, 45]. This is clinically important because two-thirds, or more, of all ER+ breast cancers are also positive for PR [10, 11]. While selective ER modulators are routinely used in therapy for PR+ breast cancer, a need for safe and effective antiprogestins remains a therapeutic goal. [10,11, 15] As off-target onapristone activity may contribute to clinically observed hepatotoxic AEs, and because onapristone more efficiently binds to PRs than GRs [24, 26, 27, 29], a strategy to attempt to minimize liver test elevations was developed based on reducing $C_{\max }$ while maintaining $C_{\min }$ at a level approximating the $C_{\min }$ achieved with onapristone $100 \mathrm{mg}$ QD (see Fig. 1). An extendedrelease tablet (ONA-ER) was selected for clinical evaluation. As reported above, ONA-ER $50 \mathrm{mg}$ BID appears to achieve the PK goals of the re-formulation program. Typical preIND toxicology studies preliminary to the IND review, as well as a non-clinical hepatic profile found no hepatotoxicity signals or lethalities, a result that enabled new clinical studies, AR18-CT-101 (NCT02052128) [8] and AR18-CT-102 (NCT02049190) [18], to be initiated.

Out of 88 subjects in clinical studies AR18-CT-101 (NCT02052128) and AR18-CT-102 (NCT02049190), five subjects (four with breast cancer and one with endometrial cancer) developed significant elevations in liver tests and serum bilirubin suggesting cholestatic injury. However, the role of progressive malignant disease with liver metastases was considered, by the DRC, a more likely cause in all four of the subjects with breast cancer. In the case of the acute elevation of ALP and GGT from elevated baseline values in a subject with endometrial cancer with lymph node metastases (see Fig. 2), an independent causality assessment by a hepatologist (J.H.L.), presented above, suggested that ONAER was unlikely to be the cause ( $<25 \%$ likelihood), based, especially, the fact that ONA-ER was resumed without incident at a lower dose, representing a negative re-challenge. Even if the liver test elevations were due to ONA-ER, the case suggests that such elevations can be managed by dose interruption and reduction, as currently recommended in the ONA-ER investigator brochure.

Overall, 54 subjects (61.0\%) experienced any ONA-ERrelated AE. In terms of liver-related treatment-emergent AEs, ALT and AST elevations occurred in $20.0 \%$ of subjects with known liver metastases, compared with $6.0 \%$ (ALT) and $9.5 \%$ (AST) of subjects without known liver metastases. The only grade 3-4 ALT elevation, and three out of four grade 3-4 AST elevations, occurred in subjects with liver metastases. Gamma-glutamyl transpeptidase elevation has low specificity for liver disease, thus the significance of $9.0 \%$ of subjects with grade 3-4 elevations is not clear.

Although no clinical signal of significant hepatotoxicity is manifest in the current liver safety database, it cannot be ruled out because of the relatively small total number of patients and the high prevalence of liver metastases. Thus, careful liver test monitoring is proposed for the planned larger phase II-III studies. It is recommended that grade 3 AST, ALT, or bilirubin elevation be managed by study drug interruption, then re-starting at a lower dose once the values resolve to grade 1 or less (ONA-ER investigator's brochure). This should be adequate to assure subject safety and to characterize the hepatic safety profile of ONA-ER. The risk/benefit assessment in oncology trials is substantially different from many other therapeutic areas such as 
contraception, the original focus of onapristone discovery. Thus, liver test elevations observed in the oncology development program, if observed in future studies and managed appropriately, should not preclude the continued development of ONA-ER for patients with PR+ cancers.

\section{Conclusions}

Onapristone extended release is a newer formulation of this unique PR antagonist that holds promise in the management of $\mathrm{PR}+$ breast and gynecological conditions. Onapristone extended release $50 \mathrm{mg}$ BID is projected to provide pharmacologic suppression of the PR at doses that should result in lower $C_{\max }$, compared with previous clinical experience with onapristone $100 \mathrm{mg}$ QD. As larger numbers of trial subjects are treated with ONA-ER, it can be better determined if ONA-ER results in a diminished risk for toxicities, including hepatotoxicity. To date, no clinical trial subject receiving ONA-ER has developed liver test elevations meeting Hy's Law criteria [33] or other clinically significant hepatic injury considered to be drug related. The risk/benefit assessment in oncology is substantially different from many other therapeutic areas, and thus the elevated liver tests observed in the oncology development program, if observed in future studies but managed appropriately, should not preclude the continued development of ONA-ER.

Acknowledgements We thank Dr. Jacques Bonneterre for his review of the manuscript.

\section{Compliance with ethical standards}

Funding This study was supported by Context Therapeutics. Context Therapeutics was involved in all aspects of the study (design and conduct of the study; collection, management, analysis, and interpretation of data; preparation, review, and approval of the manuscript; and decision to submit the manuscript for publication).

Conflict of interest James H. Lewis has no conflicts of interest that are directly relevant to the content of this article. Alice S. Bexon received payment as a medical writer. Todd Shearer is a paid consultant to Context Therapeutics and was compensated for his time performing pharmacokinetic analyses. William Rencher is a paid consultant to Context Therapeutics. Evan Dick and William Rencher are stock owners of Context Therapeutics. Martin Lehr is the CEO and stock owner of Context Therapeutics. Paul H. Cottu, Mario Campone, Andrea Varga, and Antoine Italiano were the principal investigators for the clinical trials and received salary support from BioTrial, the contract research organization that managed the phase I-II trials.

Data sharing The datasets generated during and/or analyzed during the current analysis are not publicly available because access to pharmacovigilance data must always be considered in respect to European Union laws, which protect the patient's rights to personal privacy. This does not alter our adherence to Drug Safety policies on sharing data and materials, as upon reasonable request, the data may be made available by contacting the authors.
Ethics approval This observational analysis was based on safety data extracted from a safety database. Clinical trial registration and ethical approval were not required for this analysis. This article also does not contain any data from animal studies performed by any of the authors.

Consent to participate Cumulative safety data from a European safety surveillance database were summarized in this observational analysis. No identifying patient information was reported; therefore, no additional informed consent was required.

Open Access This article is licensed under a Creative Commons Attribution-NonCommercial 4.0 International License, which permits any non-commercial use, sharing, adaptation, distribution and reproduction in any medium or format, as long as you give appropriate credit to the original author(s) and the source, provide a link to the Creative Commons licence, and indicate if changes were made. The images or other third party material in this article are included in the article's Creative Commons licence, unless indicated otherwise in a credit line to the material. If material is not included in the article's Creative Commons licence and your intended use is not permitted by statutory regulation or exceeds the permitted use, you will need to obtain permission directly from the copyright holder. To view a copy of this licence, visit http://creativecommons.org/licenses/by-nc/4.0/.

\section{References}

1. Katkam RR, Gopalkrishnan K, Chwalisz K, Schillinger E, Puri CP. Onapristone (ZK 98.299): a potential antiprogestin for endometrial contraception. Am J Obstet Gynecol. 1995;173(3 Pt 1):779-87.

2. Noguchi S, Miyauchi K, Nishizawa Y, Koyama H. Induction of progesterone receptor with tamoxifen in human breast cancer with special reference to its behavior over time. Cancer. 1988;61(7):1345-9.

3. Klijn JG, de Jong FH, Bakker GH, Lamberts SW, Rodenburg CJ, Alexieva-Figusch J. Antiprogestins, a new form of endocrine therapy for human breast cancer. Cancer Res. 1989;49(11):2851-6.

4. Robertson JF, Willsher PC, Winterbottom L, Blamey RW, Thorpe $\mathrm{S}$. Onapristone, a progesterone receptor antagonist, as first-line therapy in primary breast cancer. Eur J Cancer. 1999;35(2):214-8.

5. Perrault D, Eisenhauer EA, Pritchard KI, Panasci L, Norris B, Vandenberg T, et al. Phase II study of the progesterone antagonist mifepristone in patients with untreated metastatic breast carcinoma: a National Cancer Institute of Canada Clinical Trials Group study. J Clin Oncol. 1996;14(10):2709-12.

6. Jonat W, Girurescu M, Robertson JFR. The clinical efficacy of progesterone antagonists in breast cancer. In: Robertson JFR, Nicholson RI, Hayes DF, editors. Endocrine therapy of breast cancer, Chapter 8. London: Martin Dunitz Ltd, Taylor and Francis; 2002. p. 117-24.

7. Jonat W, Bachelot T, Ruhstaller T, Kuss I, Reimann U, Robertson JF. Randomized phase II study of lonaprisan as second-line therapy for progesterone receptor-positive breast cancer. Ann Oncol. 2013;24(10):2543-8.

8. Cottu PH, Bonneterre J, Varga A, Campone M, Leary A, Floquet $\mathrm{A}$, et al. Phase I study of onapristone, a type I antiprogestin, in female patients with previously treated recurrent or metastatic progesterone receptor-expressing cancers. PLoS ONE. 2018;13(10):e0204973.

9. Koivisto-Korander R, Leminen A, Heikinheimo O. Mifepristone as treatment of recurrent progesterone receptor-positive uterine leiomyosarcoma. Obstet Gynecol. 2007;109(2 Pt 2):512-4. 
10. Lanari C, Wargon V, Rojas P, Molinolo AA. Antiprogestins in breast cancer treatment: are we ready? Endocr Relat Cancer. 2012;19(3):R35-50.

11. Bae SY, Kim S, Lee JH, Lee HC, Lee SK, Kil WH, et al. Poor prognosis of single hormone receptor-positive breast cancer: similar outcome as triple-negative breast cancer. BMC Cancer. 2015; $15: 138$

12. Daniel AR, Gaviglio AL, Knutson TP, Ostrander JH, D'Assoro $\mathrm{AB}$, Ravindranathan $\mathrm{P}$, et al. Progesterone receptor-B enhances estrogen responsiveness of breast cancer cells via scaffolding PELP1- and estrogen receptor-containing transcription complexes. Oncogene. 2015;34(4):506-15.

13. Singhal H, Greene ME, Tarulli G, Zarnke AL, Bourgo RJ, Laine $\mathrm{M}$, et al. Genomic agonism and phenotypic antagonism between estrogen and progesterone receptors in breast cancer. Sci Adv. 2016;2(6):e1501924.

14. Finlay-Schultz J, Gillen AE, Brechbuhl HM, Ivie JJ, Matthews SB, Jacobsen BM, et al. Breast cancer suppression by progesterone receptors is mediated by their modulation of estrogen receptors and RNA polymerase III. Cancer Res. 2017;77(18):4934-46.

15. Singhal H, Greene ME, Zarnke AL, Laine M, Al Abosy R, Chang $\mathrm{YF}$, et al. Progesterone receptor isoforms, agonists and antagonists differentially reprogram estrogen signaling. Oncotarget. 2018;9(4):4282-300.

16. Knutson TP, Truong TH, Ma S, Brady NJ, Sullivan ME, Raj G, et al. Posttranslationally modified progesterone receptors direct ligand-specific expression of breast cancer stem cell-associated gene programs. J Hematol Oncol. 2017;10(1):89.

17. Lamb CA, Fabris VT, Jacobsen B, Molinolo AA, Lanari C. Biological and clinical impact of imbalanced progesterone receptor isoform ratios in breast cancer. Endocr Relat Cancer. 2018;ERC-18-0179.

18. Jayaram A, Nowakowska K, Mateo J, et al. Phase 1-2 study of progesterone receptor $(\mathrm{PR})$ inhibition with extended-release (ER) onapristone (ONA) alone or in combination with abiraterone (AA) in patients (pts) with castration-resistant prostate cancer (CRPC) incorporating plasma DNA analysis to define androgen receptor (AR) status. Ann Oncol. 2017;28(Suppl 7):vii30.

19. Lewis JH. Drug-induced liver injury throughout the drug development life cycle: where we have been, where we are now, and where we are headed. Perspectives of a clinical hepatologist. Pharm Med. 2013:27;165-91.

20. Uetrecht J. Mechanistic studies of idiosyncratic DILI: clinical implications. Front Pharmacol. 2019;10:837.

21. Luetjens CM, Didolkar A, Kliesch S, Paulus W, Jeibmann A, Bocker W, et al. Tissue expression of the nuclear progesterone receptor in male non-human primates and men. J Endocrinol. 2006;189(3):529-39.

22. Ciocca DR, Jorge AD, Jorge O, Milutin C, Hosokawa R, Diaz Lestren M, et al. Estrogen receptors, progesterone receptors and heat-shock $27-\mathrm{kD}$ protein in liver biopsy specimens from patients with hepatitis B virus infection. Hepatology. 1991;13(5):838-44.

23. Zakula Z, Moudgil VK. Interaction of rat liver glucocorticoid receptor with a newly synthesized antisteroid ZK98299. Biochim Biophys Acta. 1991;1092(2):188-95.

24. Pooley CL, Edwards JP, Goldman ME, Wang MW, Marschke KB, Crombie DL, et al. Discovery and preliminary SAR studies of a novel, nonsteroidal progesterone receptor antagonist pharmacophore. J Med Chem. 1998;41(18):3461-6.

25. Kraml J, Kolinska J, Sinkora J, Zakostelecka M, Kadlecova L, Hirsova D, et al. Glucocorticoid agonistic and antagonistic effects of mifepristone and onapristone on thymocyte subset composition and CD26/dipeptidyl peptidase IV activity in infant male rats. J Steroid Biochem Mol Biol. 2003;87(1):85-96.
26. Miner JN, Tyree C, Hu J, Berger E, Marschke K, Nakane M, et al. A nonsteroidal glucocorticoid receptor antagonist. Mol Endocrinol. 2003;17(1):117-27.

27. Afhuppe W, Beekman JM, Otto C, Korr D, Hoffmann J, Fuhrmann U, et al. In vitro characterization of ZK 230211: a type III progesterone receptor antagonist with enhanced antiproliferative properties. J Steroid Biochem Mol Biol. 2010;119(1-2):45-55.

28. Small B, Millard CEF, Kisanga EP, Burman A, Anam A, Flannery $\mathrm{C}$, et al. The selective progesterone receptor modulator ulipristal acetate inhibits the activity of the glucocorticoid receptor. J Clin Endocrinol Metab. 2020;105(3):716-34.

29. Nath R, Bhakta A, Moudgil VK. ZK98299: a new antiprogesterone: biochemical characterization of steroid binding parameters in the calf uterine cytosol. Arch Biochem Biophysics. 1992;292(1):303-10.

30. Magklara A, Smith CL. A composite intronic element directs dynamic binding of the progesterone receptor and GATA-2. Mol Endocrinol. 2009;23(1):61-73.

31. Chung HH, Sze SK, Tay AS, Lin VC. Acetylation at lysine 183 of progesterone receptor by p300 accelerates DNA binding kinetics and transactivation of direct target genes. J Biol Chem. 2014;289(4):2180-94.

32. Chalasani NP, Hayashi PH, Bonkovsky HL, Navarro VJ, Lee WM, Fontana RJ, et al. ACG clinical guideline: the diagnosis and management of idiosyncratic drug-induced liver injury. Am J Gastroenterol. 2014;109(7):950-66.

33. Lewis JH. The art and science of diagnosing and managing druginduced liver injury in 2015 and beyond. Clin Gastroenterol Hepatol. 2015;13(12):2173-89.e8.

34. Lim SM, Kim YN, Park KH, Kang B, Chon HJ, Kim C, et al. Bone alkaline phosphatase as a surrogate marker of bone metastasis in gastric cancer patients. BMC Cancer. 2016;16:385.

35. Mori K, Janisch F, Parizi MK, Mostafaei H, Lysenko I, Enikeev DV, et al. Prognostic value of alkaline phosphatase in hormonesensitive prostate cancer: a systematic review and meta-analysis. Int J Clin Oncol. 2020;25(2):247-57.

36. Corti A, Franzini M, Paolicchi A, Pompella A. Gamma-glutamyltransferase of cancer cells at the crossroads of tumor progression, drug resistance and drug targeting. Anticancer Res. 2010;30(4):1169-81.

37. Seebacher V, Polterauer S, Grimm C, Rahhal J, Hofstetter G, Bauer EM, et al. Prognostic significance of gamma-glutamyltransferase in patients with endometrial cancer: a multi-centre trial. $\mathrm{Br}$ J Cancer. 2012;106(9):1551-5.

38. Rockey DC, Seeff LB, Rochon J, Freston J, Chalasani N, Bonacini $\mathrm{M}$, et al. Causality assessment in drug-induced liver injury using a structured expert opinion process: comparison to the Roussel-Uclaf causality assessment method. Hepatology. 2010;51(6):2117-266.

39. Ryan CJ, Smith MR, Fizazi K, Saad F, Mulders PF, Sternberg $\mathrm{CN}$, et al. Abiraterone acetate plus prednisone versus placebo plus prednisone in chemotherapy-naive men with metastatic castrationresistant prostate cancer (COU-AA-302): final overall survival analysis of a randomised, double-blind, placebo-controlled phase 3 study. Lancet Oncol. 2015;16(2):152-60.

40. Fizazi K, Tran N, Fein L, Matsubara N, Rodriguez-Antolin A, Alekseev BY, et al. Abiraterone plus prednisone in metastatic, castration-sensitive prostate cancer. N Engl J Med. 2017;377(4):352-60.

41. Klein-Hitpass L, Cato AC, Henderson D, Ryffel GU. Two types of antiprogestins identified by their differential action in transcriptionally active extracts from T47D cells. Nucleic Acids Res. 1991;19(6):1227-344.

42. Elger W, Bartley J, Schneider B, Kaufmann G, Schubert G, Chwalisz K. Endocrine pharmacological characterization of progesterone antagonists and progesterone receptor modulators 
with respect to PR-agonistic and antagonistic activity. Steroids. 2000;65(10-11):713-23.

43. El Etreby MF, Liang Y. Effect of antiprogestins and tamoxifen on growth inhibition of MCF-7 human breast cancer cells in nude mice. Breast Cancer Res Treat. 1998;49(2):109-17.

44. Nishino T, Ishibashi K, Hirtreiter C, Nishino Y. Potentiation of the antitumor effect of tamoxifen by combination with the antiprogestin onapristone. J Steroid Biochem Mol Biol. 2009;116(3-5):187-90.

45. Mohammed H, Russell IA, Stark R, Rueda OM, Hickey TE, Tarulli GA, et al. Progesterone receptor modulates ERalpha action in breast cancer. Nature. 2015;523(7560):313-7.

\section{Affiliations}

\section{James H. Lewis ${ }^{1} \oplus$ - Paul H. Cottu ${ }^{2}$ - Martin Lehr ${ }^{3}$ - Evan Dick ${ }^{3}$ - Todd Shearer ${ }^{3}$ - William Rencher ${ }^{3,4}$ - Alice S. Bexon ${ }^{5}$. Mario Campone ${ }^{6} \cdot$ Andrea Varga $^{7} \cdot$ Antoine Italiano $^{8}$}

Paul H. Cottu

paul.cottu@curie.fr

Martin Lehr

mlehr@contexttherapeutics.com

Evan Dick

evandick2022@gmail.com

Todd Shearer

todd.shearer@yahoo.com

William Rencher

brencher@contexttherapeutics.com

Alice S. Bexon

alice.bexon@bexonclinical.com

Mario Campone

mario-campone@ico.unicancer.fr

Andrea Varga

andrea.varga@igr.fr

Antoine Italiano

a.italiano@bordeaux.unicancer.fr
1 Division of Gastroenterology and Hepatology, Georgetown University Hospital, 3800 Reservoir Road NW, Washington, DC 20007, USA

2 Department of Medical Oncology, Institut Curie, Paris, France

3 Context Therapeutics LLC, Philadelphia, PA, USA

4 Drug and Device Development Solutions LLC (D3S), Raleigh-Durham, NC, USA

5 Bexon Clinical Consulting, Upper Montclair, NJ, USA

6 Department of Medical Oncology, Institut de Cancérologie de l'Ouest-René Gauducheau, Nantes, France

7 Department of Drug Development (DITEP), Gustave Roussy, Villejuif, France

8 Department of Medicine, Institut Bergonié, Bordeaux, France 